\title{
Cobertura municipal da educação profissional via regime de colaboração: uma prática possível?*
}

\author{
Donaldo Bello de Souza \\ Marise Nogueira Ramos \\ Neise Deluiz
}

\section{Resumo}

$\bigcirc$ artigo visa à problematização do envolvimento dos sistemas municipais públicos de educação na cobertura das demandas locais por Educação Profissional, tomando por base a possibilidade de realizar-se via Regime de Colaboração entre os entes federados. De modo a exemplificar as reflexões realizadas, evocam-se alguns dos resultados de pesquisa de survey, de caráter descritivo e exploratório, realizada junto a Municípios do Estado do Rio de Janeiro. Como conclusão mais geral, constata, de um lado, que a cooperação advinda da União e dos Estados pela via do Regime de Colaboração vem se mostrando tímida ao atendimento desta modalidade de educação, abrindo espaço para a atuação do setor pri-

\section{Donaldo Bello de Souza}

Doutor em Educação, UFRJ

Professor Adjunto da área de

Economia da Educação, UERJ

Coordenador do Núcleo de

Estudos em Políticas de Educação (NUEPE), UERJ

donaldosouza@hotmail.com

Marise Nogueira Ramos

Doutora em Educação, UFF

Professora Adjunta da Faculdade de

Educação e do Programa de

Pós-Graduação em Políticas Públicas

e Formação Humana, UERJ

Professora do CEFET/RJ

Pesquisadora, EPSJV/Fiocruz marise-ramos@uol.com.br

\section{Neise Deluiz}

Doutora em Educação, UFRJ Professora Titular e Coordenadora da Linha de Pesquisa em Trabalho,

Meio Ambiente e Educação do

Mestrado em Educação, UNESA ndeluiz@uol.com.br vado em sua cobertura, e, de outro, que a produção científica neste campo ainda se mostra incipiente, dificultando a compreensão, entre outros aspectos, da identidade da Educação Profissional no âmbito dos sistemas educacionais, particularmente municipal, de modo a verificar a pertinência de se considerála, formalmente, como objeto de ação cooperada entre os entes federados.

Palavras-chave: Educação profissional. Regime de colaboração. Educação básica. Privatização da educação.

Abstract Municipal covering of the Professional Education through a Contribution

"Uma versão adaptada deste trabalho foi apresentada no "V Congresso da Associação Latino-Americana de Sociologia do Trabalho (Alast)", realizado em Montevideo, Uruguay, de 18 a 20 de abril de 2007. 


\section{Regimen: a possible practice?}

The article discusses the difficulties of commitment of the public municipal education system with the local demands for Professional Education, taking in consideration the possibility to do it through a Contribution Regimen among the federate beings. In order to demonstrate these reflections, the article shows some of the results of a research conducted in various municipalities of the State of Rio de Janeiro. As a general result we conclude that the Government Cooperation through the Contribution System is still timid and fragile when it comes to professional education, creating space for the private sector (the S System as Senai, Senat among others) to fill this gap. On the other hand, the scientific production in this field is in its early stages, making it difficult to understand the role of Professional Education in the scope of the educational systems, mainly in the municipal sphere as an object of cooperation among the federate beings.

Keywords: Professional education. Contribution regimen. Basic education. Privatization of the education.

\section{Resumen}

\section{Cobertura municipal de la} Educación Profesional por la via del Régimen de Colaboración: una práctica posible?

El artículo tiene como objetivo la problematización del envolvimiento de los sistemas municipales públicos de educación en la cobertura de las demandas locales por Educación Profesional, tomando por base tres ejes analíticos centrales: el Régimen de Colaboración entre los entes federados, las asociaciones público-privado y las relaciones entre el desarrollo económico local y la promoción de la Educación Profesional. De modo a ilustrar las reflexiones realizadas, son evocados algunos de los resultados de investigación de survey, de carácter descriptivo y explorador, realizada en los Municipios del Estado de Rio de Janeiro. Como conclusión más general, se constata que la cooperación advenida de la Unión y de los Estados por la vía del Régimen de Colaboración, se viene mostrando tímida a su atención, sobresaliendo la creciente actuación del sector privado en su cobertura, notadamente del "Sistema S", al margen de la existencia de políticas públicas que visen, sistemáticamente, el acompañamiento y evaluación de esas iniciativas. Es notable también que esas acciones exponen una dupla desvinculación: de un lado, con relación a eventuales políticas municipales y/o estaduales de generación de trabajo y renta, $y$, de otro, en lo que remite a los Programas y Proyectos dirigidos a la atención de la Educación de Jóvenes y de Adultos (EJA).

Palabras clave: Educación profesional. Régimen de colaboración. Asociaciones público-privado.

\section{Introdução}

Elevados pela Constituição Federal de 1988 (BRASIL, 1988), à condição de entes federados, os Municípios, na área educacio- 
nal, passaram a criar seus próprios sistemas de ensino', relativamente autônomos em relação aos sistemas federal e estaduais², tendo como prioridade o atendimento ao Ensino Fundamental e Pré-escolar (Artigo $211, \S$ $\left.2^{\circ}\right)$, este último, mais tarde - com base na Emenda Constitucional $n^{\circ}$. 14, (BRASIL, 1996), de 12 de setembro de 1996, e pela Lei de Diretrizes e Bases da Educação Nacional - LDBEN, Lei n. 9.424, de 24 de dezembro de 1996 (BRASIL, 1996), que a regulamenta, renomeado Educação Infantil (0 a 6 anos).

Em termos práticos, o novo ordenamento jurídico irá repercutir numa maior responsabilização direta do Município na captação de suas próprias demandas, no monitoramento de gastos e na inspeção do cumprimento das metas federais e/ou estaduais estabelecidas, agora não unicamente pelo poder público local, mas, também, pela via da responsabilização da sociedade civil (MENEZES, 2001; JACOBI, 2002; NOGUEIRA, 1997). Criará, ainda, espaço para práticas sociais voluntárias de apoio à escola, de caráter tipicamente assistencial (CALDERÓN; MARIM, 2002, 2003), ocorrendo, a um só tempo, elevado controle dos níveis superiores do governo sobre os fluxos financeiros e as transferências intergovernamentais (GONÇALVES, 1998), visivelmente ancorado na manutenção da centralização normativa e política em relação à instância executora (MONTAÑO, 2003; VIEIRA; FREITAS, 2003).
Do ponto de vista da oferta dos níveis e modalidades de educação cujas demandas se vêm fazendo notar em âmbito local, observam-se que as dificuldades para o seu atendimento são muitas. No caso da Formação de Professores, da Educação a Distância, da Educação Especial e da Educação Indígena, apesar de contarem com a definição de algumas políticas públicas específicas (federais, regionais ou locais), ainda expõem inúmeras dificuldades de implantação, que se estendem da ausência ou precariedade de recursos à necessidade de revisão de muitos dos pontos legais que prevêem sua oferta. No tocante à realidade da Educação Infantil, da Educação de Jovens e Adultos (EJA), da Educação no Campo e, em especial, da Educação Profissional, cabe destacar que estes níveis e modalidades se apresentam ainda mais desafiadores para os Municípios, uma vez que não se encontram amparados por políticas públicas específicas de financiamento, de abrangência nacional, estando, portanto, fortemente dependentes de programas e projetos pontuais, com indefinições quanto à regularidade, qualidade e volume de recursos destinados à sua oferta (SOUZA; FARIA, 2003).

No caso do Ensino Fundamental, há consenso de que se trata do único nível de educação beneficiado pelas políticas públicas indutoras ao processo de descentralização da educação via municipaliza-

\footnotetext{
'Entendemos por sistemas de ensino "o conjunto de campos de competências e atribuições voltadas para o desenvolvimento da educação escolar que se materializam em instituições, órgãos executivos e normativos, recursos e meios articulados pelo poder público competente, abertos ao regime de colaboração e respeitadas as normas gerais vigentes" (CONSELHO NACIONAL DE EDUCAÇÃO, 2000, p. 13). De modo subjacente ao conjunto de elementos materiais e não-materiais constitutivos dos sistemas de ensino compreende-se sua formação como sobremaneira dependente do binômio educação-sociedade, já que consistem, fundamentalmente, em "um conjunto de realidades inter-relacionadas, mutuamente influenciáveis" (BONITATIBUS, 1989, p. 23), integrante de uma configuração mais ampla, caracteristicamente a sócio-cultural, o que significa que encontram-se, em última instância, dependentes dos contextos a partir dos quais se edificam e passam a interferir.

${ }^{2}$ Outras opções, previstas na esfera da Ldben 9.394/96, consistem ou na integração do Município ao sistema estadual ou, ainda, na composição com este de um sistema único de Educação Básica (Artigo 11 , Parágrafo único).
} 
ção, em que pese o fato de não terem logrado universalizá-lo com a qualidade esperada. A par das decisões políticas em torno da municipalização, marcadamente dependente das relações entre os governos subnacionais (Estados e Municípios), esse movimento será impulsionado, especialmente, com a implantação, em 1988, do Fundo de Manutenção e Desenvolvimento do Ensino Fundamental e de Valorização do Magistério (Fundef) ${ }^{3}$, de forma que as prefeituras não viessem a estar impedidas de utilizar os recursos daí derivados (BORGES, 2000). Apesar disto, o Fundef irá acentuar, sobremaneira, a debilidade do atendimento da Educação Infantil e da EJA, isto por não considerá-las em sua cobertura (CASTRO, 2001; DUARTE, 2000; VERHINE, 2000; DAVIES, $2001 a, b$; 1999; CURY, 2000; MONLEVADE, 2001, 1997; GUIMARÃES; PINTO, 2001), acabando, também, por favorecer a expansão do setor privado de ensino inclusive nessas áreas (DAVIES, 1999) ${ }^{4}$.

Em face da implantação do Fundo de Manutenção e Desenvolvimento da Educa- ção Básica e de Valorização dos Profissionais da Educação (Fundeb), em substituição ao Fundef, é esperado que tais limitações e distorções sejam superadas, já que o novo Fundo prevê a vinculação de recursos para todos os níveis da Educação Básica (Ensinos Infantil, Fundamental e Médio), incluindo a modalidade de atendimento de EJA ${ }^{5}$.

Para exemplificar as reflexões em torno da atuação dos Sistemas Municipais Públicos de Educação no campo da Educação Profissional, objetivo primeiro do presente artigo, lançou-se mão de parte dos resultados decorrente da realização de pesquisa de survey que enfocou 29 Municípios deste Estado, denominada "Mapa Estadual das Reformas Educacionais Pós-LDB 9.394/96: Leituras, Posicionamentos e Ações das Secretarias Municipais de Educação do Estado do Rio de Janeiro (2001-2004)." (SOUZA; FARIA, 2002).

Essa pesquisa, realizada pelo Núcleo de Estudos em Políticas de Educação (Nuepe) da Faculdade de Educação da Universidade do Estado do Rio de Janeiro (UERJ), ao longo dos anos 2002-2005, em seu cômputo geral,

\footnotetext{
${ }^{3}$ Criado pela EC 14/96 e pela Lei $9.424 / 96$, o Fundef consiste num fundo contábil, de âmbito estadual, que reúne $15 \%$ da arrecadação de alguns impostos -Imposto sobre Circulação de Mercadorias e Serviços (ICMS); Fundo de Participação dos Estados (FPE) e Municípios (FPM); Imposto sobre Produtos Industrializados Proporcional às Exportações (Iplex) e, ainda, com a desoneração de exportações de que trata a Lei Complementar 87 (Lei Kandir), de 13 de setembro de 1996 -, repartidos entre o governo estadual e os municipais de acordo com vários critérios legais (sendo até hoje seguido apenas o de número de matrículas no Ensino Fundamental regular público). Com isto, todos os governos contribuem com aquele percentual para o Fundo comum, sendo que a sua distribuição se dá em função do quantitativo de matrículas registrado no âmbito daquele nível de ensino, com possibilidade de complementação pela União, de modo a garantir um valor aluno/ano igual ao mínimo nacional estipulado (SOUZA; FARIA, 2004). ${ }^{4} \mathrm{~A}$ um só tempo, é postulado que o Fundef contrariaria, na prática, sua própria lógica de funcionamento, já que as transferências de recursos estariam ocorrendo, tipicamente, dos Municípios demograficamente pequenos para os de médio e até mesmo grande porte, processo no qual se verifica que, do conjunto de localidades que teriam perdendo recursos com este Fundo, $71 \%$ possuem menos de 10 mil habitantes (BREMAEKER, 2004).

${ }^{5}$ O Fundeb foi criado recentemente, a partir da EC 54, de 06 de dezembro de 2006, com vigência para os próximos 14 anos. Do ponto de vista de sua composição, decorrerá de $20 \%$ das receitas de impostos e transferências dos Estados e Municípios (o Fundef operava com 15\%), prevendo, além das arrecadações que serviam ao Fundef (veja-se nota de fim de página 3), o Imposto de Propriedade de Veículos Automotores (IPVA), o Imposto sobre Transmissão Causa Mortis e Doação (ITCMD) e a Cota Parte Municipal do Imposto Territorial Rural (ITR). Vale ressaltar que a Proposta de Emenda Constitucional (PEC) 537/97, que implicou o substitutivo aprovado pelo Senado, previa a utilização dos recursos do Programa de Integração Social / Programa de Formação do Patrimônio do Servidor Público (PIS/Pasep) na Educação Profissional do trabalhador, um dos dispositivos rejeitados pela Câmara. Contudo, a Medida Provisória (MP) 339, de 28 de dezembro de 2006, que atualmente regulamenta o Fundeb, prevê o direcionamento de recursos deste Fundo para o Ensino Médio e para a EJA integrados à Educação Profissional (Artigo 10).
} 
visou ao conhecimento acerca do conjunto das políticas em desenvolvimento pelas Secretarias Municipais de Educação (SMEs) deste Estado, no período de gestão 2001-2004, de modo a poder-se inferir sobre as dificuldades enfrentadas pelas prefeituras fluminenses face ao processo de descentralização da educação via municipalização ${ }^{6}$. Sua fase de coleta de dados ocorreu ao longo do segundo semestre de 2004, implicando remessa de questionários ao total dos 92 Secretários Municipais de Educação do Estado, contemplando, de um lado, aspectos relativos à gestão e ao financiamento da educação desses sistemas e, de outro, especificidades relativas aos níveis e modalidades de ensino por eles oferecidos ${ }^{7}$. Os quesitos referentes à Educação Profissional (ao todo 42) constam de um dos quatro formulários eletrônicos empregados, semi-uniformizados (embora com prevalência de respostas abertas), denominado "Níveis e Modalidades de Educação no Município".

Em função do hibridismo relativo ao instrumento de coleta de dados utilizado (questões abertas e fechadas), adotou-se um modelo de análise dito de "grade mista" (LAVILLE; DIONNE, 1999), ou seja, apesar de a priori possuir-se a definição de algumas categorias analíticas, fundadas, sobretudo, na consideração da literatura pertinente e no quadro operatório anteriormente elaborado, a análise dos resultados não se limitou, apenas, à verificação da presença de elementos predeterminados, ou seja, ao simples confronto entre as configurações "teórica predita" e "empírica observada" (CONTANDRIOPOULOS et al., 1997, p. 89). Levou-se em conta, portanto, um conjunto mais amplo de elementos teórico-empíricos que exprimissem importância para a investigação, tendo, inclusive, implicado ampliação do campo categórico e alterações no conteúdo de determinadas categorias ${ }^{8}$.

A adesão ao survey ocorreu por parte de $32 \%$ (29) das 92 SMEs fluminenses, expondo uma relativa equalização entre os quantitativos de respondentes pelas oito Regiões Administrativas de Governo do Estado do Rio de Janeiro, preponderantemente, com taxas de retorno localizadas acima daquele percentual, à exceção de duas únicas Regiões: Metropolitana (a que aglutina a maior quantidade de localidades) e Centro-Sul Fluminense, cujas taxas se situaram abaixo deste nível (22\% e $20 \%$, respectivamente) ${ }^{9}$.

\footnotetext{
${ }^{6}$ Em suas várias fases de execução, o survey beneficiou-se de importantes apoios provenientes tanto da Uerj-em termos da concessão de Bolsa de Pesquisa para dedicação exclusiva à investigação (Programa Prociencia), dirigida ao seu coordenador , quanto de Bolsas de IC e financiamento por parte da Fundação Carlos Chagas Filho - Amparo à Pesquisa do Estado do Rio de Janeiro (Faperi), de Bolsa Pibic do Conselho Nacional de Desenvolvimento Científico e Tecnológico (CNPq), além do apoio institucional da União Nacional dos Dirigentes Municipais de Educação (Undime-RJ).

${ }^{7}$ Ao todo, esses questionários totalizaram 423 quesitos assim distribuídos: o Formulário 1 (12 quesitos), enfocando as "Informações Gerais sobre o Município"; o Formulário 2 (3 temáticas com 40 quesitos), tratando do "Financiamento da Educação no Município"; o Formulário 3 (8 temáticas com 128 quesitos), versando sobre a "Gestão da Educação no Município" e, por fim, o Formulário 4 (9 temáticas com 243 quesitos), dedicado aos "Níveis e Modalidades de Educação no Município".

${ }^{8} \mathrm{O}$ processo de construção das categorias teórico-empíricas se pautou na busca da exclusão mútua (cada elemento ou descritor somente podendo se fazer presente numa única categoria), da homogeneidade (um mesmo conjunto categorial devendo expressar uma única dimensão de análise), da pertinência (a categoria devendo expor coesão em relação às intenções da pesquisa), da objetividade (a definição das categorias resistindo a diferentes análises) e da produtividade (a busca de categorias que permitissem fecundidade nas inferências) (BARDIN, 1977).

${ }_{9}$ Municípios que participaram do survey, por Região Administrativa de Governo do Estado (Cf. RIO DE JANEIRO, 2003): Baixadas Litorâneas, com 38\% de respostas (Armação de Búzios, Cachoeiras de Macacu, Casimiro de Abreu, São Pedro da Aldeia e Silva Jardim); Centro-Sul, com 20\% (Paty do Alferes e Três Rios); Costa Verde, com 33\% (Angra dos Reis); Médio Paraíba, com 33\% (Barra Mansa, Porto Real, Rio das Flores e Volta Redonda); Metropolitana, com 22\% (Duque de Caxias, Nova lguaçu, Queimados e São João de Meriti); Noroeste, com 38\% (Itaocara, Miracema, Natividade, Porciúncula, Varre-Sai); Norte, com 33\% (Quissamã, São Fidelis e São João da Barra) e Serrana, com 36\% (Carmo, Cordeiro, Duas Barras, Petrópolis e Teresópolis).
} 
Desse conjunto de respondentes (29), apenas duas SMEs não devolveram o Formulário 4 preenchido (Níveis \& Modalidades de Educação no Município), sendo que, dessas 27 Secretarias (29,3\% dos Municípios fluminenses), $16(17,4 \%)$ se detiveram na temática da Educação Profissional, embora nem todos os 42 quesitos previstos tivessem sido efetivamente respondidos.

Desses 16 Municípios do Estado do Rio de Janeiro respondentes à temática da Educação Profissional, 62,5\% afirmaram que suas redes públicas de ensino não a atendem, enquanto que $37,5 \%$ declararam fazêlo. Dentre o conjunto de justificativas para o não-atendimento, prevalece a explicação de que a Educação Profissional não se constitui em prioridade legal desses entes federados (50\% das respostas) e, em menor escala, a indicação de que nessas localidades ela ocorre na rede privada (20\%) ou na rede estadual (10\%), seguida da informação de que inexistem quaisquer condições locais par a sua promoção $(10 \%)^{10}$. De acordo com os respondentes, o atendimento em questão ocorre, majoritariamente $(54,5 \%)$, no âmbito do Nível Técnico da Educação Profissional, que, a partir do Decreto $n^{\circ} .5 .154$ (BRASIL, 2004), de 23 de julho de 2004, passa a corresponder à Educação Profissional Técnica de Nível Médio, e, com menor freqüência (27,3\%), no Nível Básico - atual Formação Inicial e Continuada -, não havendo menção ao Nível Tecnológico - atual Graduação e Pósgraduação Tecnológica ${ }^{11}$.

Pressupomos, então, que as ações municipais voltadas para o atendimento da
Educação Profissional, realizadas no âmbito dos sistemas de educação locais, são pouco expressivas, salvo quando ocorrem em cooperação com outras esferas de governo ou em parceria com organizações privadas, com acentuada participação destas últimas. A natureza e a efetividade desse relacionamento dependerá, em certa medida, dos princípios ético-políticos que as orientam; das estratégias formativas empregadas, incluindo propostas de aumento de escolaridade dos trabalhadores e do desenvolvimento de itinerários que aproveitem continuamente os estudos realizados.

\section{A reforma da Educação Profissional no Governo FHC: algumas implicações para os Municípios}

A Lei de Diretrizes e Bases da Educação Nacional - LDBEN (BRASIL, 1996), Lei n. 9.394, de 20 de dezembro de 1996, retirou do capítulo que dispunha sobre o Ensino Médio os dispositivos que falavam sobre a formação técnica nesta etapa da Educação Básica. Do que previa o projeto de LDBEN original da Câmara dos Deputados, restou somente o Parágrafo $2^{\circ}$ do Artigo 32, admitindo que o Ensino Médio, atendida a formação geral do educando, poderá prepará-los para o exercício de profissões técnicas.

De fato, foi o Decreto 2.208 (BRASIL, 1997), de 17 de abril de 1997, e não a LDBEN, que efetivamente regulamentou a Educação Profissional no Brasil, definindoa como o ponto de articulação entre a es-

\footnotetext{
${ }^{10}$ Do total de respostas a esse quesito (10), 10\% não permitiu categorização devido à truncagem ou ausência de coesão em relação ao enunciado do quesito.

${ }^{11}$ Do total de respostas a esse quesito (1 1), 18,2\% não explicitaram quaisquer dos níveis da Educação Profissional em questão.
} 
cola e o mundo do trabalho. Suas funções foram assim descritas: i) qualificar, requalificar e reprofissionalizar trabalhadores em geral, independente do nível de escolaridade; ii) habilitar jovens e adultos para o exercício de profissões de nível médio e de nível superior; e iii) atualizar e aprofundar conhecimentos tecnológicos voltados para o mundo do trabalho. Essas atribuições estariam condensadas, respectivamente, nos Níveis Básico, Técnico e Tecnológico da Educação Profissional, prevendo-se, ainda, cursos de atualização, aperfeiçoamento e especialização técnica.

Do ponto de vista da organização curricular, o Nível Básico da Educação Profissional (destinado à qualificação, requalificação e reprofissionalização de jovens e adultos, independente de escolarização prévia adquirida) não teve uma regulamentação própria. A titulação no Nível Técnico, por outro lado, pressupunha a conclusão do Ensino Médio, e sua oferta devia seguir uma regulamentação bastante detalhada nas Diretrizes Curriculares Nacionais (DCNs). Os currículos deveriam ser organizados em módulos - unidades pedagógicas autônomas e completas em si mesmas - que poderiam qualificar para certas ocupações e, no seu conjunto, levar a uma habilitação técnica, podendo, ainda, ser cursados em diferentes instituições. Desta forma, introduziu-se a idéia de itinerários formativos autônomos e flexíveis ${ }^{12}$.

O ponto de maior impacto desta refor$\mathrm{ma}$, entretanto, foi desvincular a formação técnica do Ensino Médio, impondo aos estudantes a disputa por duas matrículas, concomitantemente: uma no Ensino Médio pro- priamente dito e outra num curso técnico; ou deixar para cursar este último após a conclusão do Ensino Médio. Neste contexto, a oferta de cursos técnicos nas redes estaduais tendeu a diminuir, uma vez que essas deveriam priorizar o Ensino Médio, acarretando um deslocamento da Educação Profissional para os segmentos privados.

Em síntese, podemos dizer que a reforma da Educação Profissional realizada pelo governo de Fernando Henrique Cardoso (FHC), assentou-se sobre três medidas, a saber: i) constituição de um nível de formação desvinculado do pré-requisito de escolaridade; ii) separação formal e curricular dos ensinos médio e técnico, mantida a conclusão do primeiro como pré-requisito para a diplomação no segundo; iii) concepção da formação profissional em itinerários ou trajetórias flexíveis. Essas medidas conferiram à Educação Profissional uma identidade própria, desvinculada do sistema educacional formal, sendo realizada por diversas estratégias que não exclusivamente a via escolarizada.

Uma das conseqüências desta desvinculação foi que a responsabilidade pela oferta da Educação Profissional não foi imputada a nenhum sistema educacional, - que gerou uma contradição interna à LDBEN (BRASIL, 1996), perceptível ao analisarmos conjuntamente o Artigo 4, ○ Parágrafo $1^{\circ}$ do Artigo 37 e o Parágrafo único do Artigo 39. Ora, se os jovens e adultos que não tiveram acesso à educação regular em idade apropriada têm como direito e dever cursar, pelo menos, o Ensino Fundamental; se, para isto, os siste-

\footnotetext{
12 O terceiro Nível da Educação Profissional preconizado pelo Decreto 2.208/97 (BRASIL, 1997), consistiu no Tecnológico, considerado por Cunha (1998, p. 25) "o mais imprecisamente definido de todos", correspondendo à clientela egressa do Ensino Médio e técnico, visando a formação de tecnólogos em cursos superiores da área tecnológica, segundo diferentes especialidades.
} 
mas de ensino assegurarão oportunidades educacionais apropriadas, consideradas suas características, interesses, condições de vida e de trabalho; e, se enquanto matriculado ou tendo concluído o Ensino Fundamental, Médio e Superior, qualquer aluno contará com a possibilidade de acesso à Educação Profissional; não poderíamos supor que Municípios e Estados deveriam compartilhar essa responsabilidade pelo menos para jovens e adultos, em articulação com o Ensino Fundamental, nível obrigatório da educação? E em relação à formação para profissões de nível médio, não deveriam os sistemas responsáveis pelo ensino médio também responsabilizarem-se por aquela? Mesmo pertinentes, nenhuma dessas suposições foram até agora contempladas por lei, o que mantém a Educação Profissional à margem do sistema educacional.

\section{A desresponsabilização dos sistemas de} ensino com a Educação Profissional, contraposta à grande demanda ainda existente por essa modalidade de ensino, levou o governo federal a desenvolver a política de Educação Profissional com base na promoção de Programas. Os principais desses foram: i) o Programa de Expansão e Melhoria da Educação Profissional (Proep) ${ }^{13}$, implementado pelo Ministério da Educação - MEC; ii) o Programa de Profissionalização dos Auxiliares de Enfermagem (Profae) ${ }^{14}$, realizado pelo Ministério da Saúde $(M S)^{15}$; e, ainda, iii) o Plano Nacional de Educação Profissional (Planfor) ${ }^{16}$, gerido pelo Ministério do Trabalho (MTb). O Proep e o Planfor conferiram um significativo apoio aos segmentos comunitários, definindo-se a iniciativa privada como os principais parceiros na oferta da Educação Profissional.

Enquanto o Planfor teve como fonte principal de financiamento os recursos do Fundo de Amparo ao Trabalhador (FAT), os outros dois programas contaram com empréstimos do Banco Interamericano de Desenvolvimento (BID). O problema do financiamento externo à educação tem sido abordado por alguns estudos (FONSECA, 1996), posto que as exigências dos organismos internacionais, por vezes distantes

\footnotetext{
${ }^{13}$ O Proep consiste numa iniciativa do MEC em parceria com o Ministério do Trabalho e Emprego (MTE) e com o Banco Interamericano de Desenvolvimento (BID) voltado para a implantação de um sistema de Educação Profissional no país, através de um conjunto de ações a serem desenvolvidas em articulação com diversos segmentos da sociedade. Este programa teve como finalidade a expansão, modernização, melhoria de qualidade educacional e a permanente atualização profissional no país, por meio da ampliação e diversificação da oferta de vagas, da adequação de currículos e cursos às necessidades do mundo do trabalho; da qualificação e reprofissionalização de trabalhadores, independente do nível de escolaridade e da formação e habilitação de jovens e adultos nos níveis médio (técnico) e superior (tecnológico).

${ }^{14} \mathrm{O}$ Profae é uma iniciativa do Ministério da Saúde, cujo objetivo principal consiste na qualificação e profissionalização dos trabalhadores da área de enfermagem de nível básico e técnico. O Profae ofereceu três modalidades de cursos gratuitos para os trabalhadores da área de enfermagem: i) Curso de Qualificação Profissional de Auxiliar de Enfermagem, para os trabalhadores que concluíram o Ensino Fundamental (antigo $1^{\circ} \mathrm{grau}$ ); ii) Complementação do Ensino Fundamental, para os trabalhadores que não o concluíram e Auxiliar de Enfermagem; iii) Curso de Técnico de Enfermagem, para os trabalhadores que têm o Certificado de Conclusão do Ensino Médio (antigo $2^{\circ}$ grau) e o Certificado de Conclusão do Curso de Auxiliar de Enfermagem.

${ }^{15}$ Ambos os programas realizam-se sob o modelo de co-financiamento: $50 \%$ dos recursos provêm do BID e $50 \%$ do Brasil, dos quais metade advém do FAT.

${ }^{16}$ A partir de 1995 foi implementado, no âmbito do MTb, o Planfor, que pretendia mobilizar e articular toda a capacidade e competência disponível de Educação Profissional no país, governamental e não governamental, com a meta de qualificar/ requalificar anualmente, pelo menos $20 \%$ da população economicamente ativa. O Planfor veio a ser executado de forma descentralizada, através dos Planos Estaduais de Qualificação (PEQs), elaborados e coordenados pelas Secretarias Estaduais de Trabalho, que contrata Instituições Executoras - instituições empresariais, universidades, Escolas Técnicas Federais/ Estaduais, ONGs, centrais sindicais, entre outras -, para ministrar cursos de qualificação profissional.
} 
das reais necessidades sociais do país, causam grandes custos políticos, sociais e financeiros, sem que se revertam em benefícios concretos para a sociedade.

Além disto, normalmente, os maiores custos financeiros são de responsabilidade nacional. Ainda que as condições dos acordos sigam as regras do co-financiamento, de modo que o país executor do projeto e o Banco entrem, cada um deles, com $50 \%$ do financiamento, é o país que deve gastar primeiro, sendo gradativamente ressarcido pelo Banco. A nãoaplicação dos recursos nestes moldes obriga o país ao pagamento de taxas de compromisso, juros e ajustes cambiais, além dos custos originalmente previstos para a execução do projeto. Esse mecanismo fez com que em convênios firmados nas décadas de 70 e de $80^{17}$, o Brasil tenha comparecido com $65,5 \%$ e $78,0 \%$ dos custos inicialmente previstos.

Um dos princípios da política de educação profissional do governo federal no período analisado foi a restrição ao aumento do número de instituições federais de educação profissional. A criação de novas escolas só poderia ocorrer por iniciativa dos estados ou dos municípios, isoladamente, ou em associação com o setor privado; ou, ainda, por meio de entidades privadas sem fins lucrativos, isoladamente ou em associação com o setor público. Promoveu-se, assim, um significativo apoio aos segmentos comunitários, definindo-se a iniciativa privada como os principais responsáveis pela educação profissional. Note-se que o Proep - principal suporte da política de educação profissional do governo federal - exigia a comprovação da sustentabilidade das ações apoiadas na forma de investimentos. Face à não-previsão de financiamento público da educação profissional, foi a iniciativa privada que apresentou maiores condições nesse sentido, enquanto as instituições públicas, por sua vez, demonstravam disposição e condições para elevar sua arrecadação própria mediante a venda de serviços e estratégias afins.

A abrangência desses Programas não parece ter sido suficiente para atingir diretamente os sistemas municipais de ensino, apesar de a Lei $n^{\circ} .9 .649$ (BRASIL, 1998), de 27 de maio de 1998, ter definido que a expansão da oferta da Educação Profissional, mediante a criação de novas unidades por parte da União, só poderia ocorrer em parceria com governos estaduais, municipais ou setores privados. Isto poderia levar algumas prefeituras a assumirem parte da oferta e do financiamento da Educação Profissional em suas localidades, por exemplo, doando terrenos ou cedendo professores. Essas iniciativas, entretanto, não foram significativas a ponto de sugerir uma atuação direta dos sistemas municipais de ensino neste campo educacional. Quando existe a oferta local da Educação Profissional, predominam iniciativas de outras instâncias, que não as SMEs.

\footnotetext{
${ }^{17} \mathrm{Na}$ área do ensino técnico, o Banco Internacional para a Reconstrução e o Desenvolvimento (Bird) já financiou pelo menos dois grandes projetos. O primeiro foi firmado em 1971, com execução prevista até 1978, e objetivava a implantação de seis Centros de Engenharia de Operação nas Escolas Técnicas Federais. Este projeto levou nove anos para ser concluído e deu origem aos Centros Federais de Educação Tecnológica (CEFETs) do Rio de Janeiro, do Paraná e de Minas Gerais. O segundo foi o projeto Edutec, previsto para o período de 1980 a 1984, destinado às escolas industriais e agrícolas das redes estadual e federal.
} 


\section{A Educação Profissional no Governo Lula: novas possibilidades? 18}

Os compromissos assumidos pelo Governo Lula quanto à Educação Profissional implicavam sua reconstrução como política pública, visando a "corrigir distorções de conceitos e de práticas decorrentes de medidas adotadas pelo governo anterior, que de maneira explícita dissociaram a educação profissional da educação básica, aligeiraram a formação técnica em módulos dissociados e estanques, dando um cunho de treinamento superficial à formação profissional e tecnológica de jovens e adultos trabalhadores" (BRASIL, 2005, p. 2).

Dentre essas correções, uma das mais relevantes, devido ao seu fundamento político e por se tratar de um compromisso assumido com a sociedade na proposta de governo, foi a revogação do Decreto 2.208/ 97 (BRASIL, 1997), restabelecendo-se a possibilidade de integração curricular dos ensinos médio e técnico, de acordo com o que dispõe o Artigo 36 da LDBEN (BRASIL, 1996). De fato, isto se fez pelo Decreto 5.154/04 (BRASIL, 2004).

A nova legislação não mais definiu a Educação Profissional em níveis, por compreender que esses se referem exclusivamente à organização da educação nacional e não a uma modalidade específica. Tentouse, assim, evitar que a política de Educação Profissional levasse à constituição de um sistema educacional paralelo. A Educação Profissional ficou organizada, então, em cursos e programas, ao invés de níveis.
Conforme dispõe o Artigo 1 do novo decreto, esses podem ser: i) de formação inicial e continuada de trabalhadores; ii) de educação técnica de nível médio; e iii) de graduação e de pós-graduação.

Destacou-se a necessidade de a Educação Profissional observar a estrutura sócio-ocupacional e tecnológica da economia e articular esforços das áreas da educação, do trabalho e emprego, e da ciência e tecnologia. Os cursos de formação inicial e continuada (que, a grosso modo, compreenderiam aqueles definidos pelo antigo decreto como cursos de nível básico), ao invés de serem fragmentados e dispersos conforme predominou na política anterior, especialmente sob a égide do Planfor, deveriam ser ofertados segundo itinerários formativos, objetivando o desenvolvimento de aptidões para a vida produtiva e social, articulando-se com a EJA, de modo que a qualificação para o trabalho também implicasse elevação do nível de escolaridade do trabalhador.

Outra medida muito significativa trazida pelo novo decreto, e que esteve na base das disputas entre os segmentos progressistas e conservadores, foi a possibilidade de se integrar a Educação Profissional Técnica de Nível Médio ao Ensino Médio, ainda que se tenha mantido a oferta concomitante e subseqüente desses cursos, conforme disposto pelo Artigo 4.

A nova maneira de se compreender a Educação Profissional, qual seja, não como um sistema paralelo, mas organicamente relacionada com a Educação Básica, traz

\footnotetext{
${ }^{18}$ Uma análise crítica sobre o percurso controvertido da política de Educação Profissional no Governo Lula pode ser encontrada em Frigotto, Ciavatta e Ramos (2005b).
} 
implicações importantes quanto à responsabilização dos sistemas de ensino na sua oferta, em razão tanto da articulação da formação inicial e continuada com a EJA, quanto da integração da formação técnica com o Ensino Médio. Os sistemas de ensino, ao terem a obrigação com o Ensino Fundamental e Médio na modalidade EJA, podem ou mesmo devem articulá-los com a Educação Profissional, precisando dispor, então, de estrutura física e de recursos financeiros para este fim. Igualmente, podendo oferecer o Ensino Médio técnico, não faz sentido que se financie somente a formação geral, mas também a formação específica que assegura a Educação Profissional técnica de nível médio.

Deve-se notar, entretanto, que tal reorientação conceptual não surtiu efeitos políticos imediatos significativos. De fato, a formação inicial e continuada de trabalhadores tem sido realizada por meio do Programa Nacional de Qualificação do Ministério do Trabalho e Emprego (PNQ/MTE), sem uma consolidação dos referenciais de articulação com a Educação Básica ${ }^{19}$. Por parte do MEC, tem-se a hegemonia do Programa Escola de Fábrica, que visa a dar a formação profissional inicial a jovens entre 16 e 24 anos, matriculados na Educação Básica (nas modalidades regular ou EJA), cujas famílias tenham renda per capita de até um salário mínimo. Ambos os Programas se assentam no relacionamento entre os setores público e privado, sem, entretanto, contar com um envolvimento direto e explícito dos sistemas de ensino, salvo o federal, posto que, no Programa Escola de Fábrica, a certificação pode ficar a encargo dos CEFETs.
Com direcionamento mais explícito, porém, reconhecemos a relevância que pode vir a assumir o Programa de Integração da Educação Profissional ao Ensino Médio na Modalidade de Educação de Jovens e Adultos (Proeja), lançado pelo Ministério da Educação. Este Programa incentiva as instituições públicas dos diversos sistemas de ensino a oferecer o Ensino Médio integrado à Educação Profissional destinado a jovens acima de 18 anos e adultos que tenham cursado apenas $\circ$ Ensino Fundamental. Apresenta-se como objetivo desse Programa a ampliação dos espaços públicos da Educação Profissional para os adultos e uma estratégia que contribui para a universalização da Educação Básica. A consecução desses objetivos, pressupondo o compromisso dos sistemas de ensino com a Educação Profissional, entretanto, precisa ser investigada à medida que o programa se efetive.

Por fim, cabe acompanhar, ainda, a consolidação do Ensino Médio integrado à Educação Profissional como política pública ${ }^{20}$. Alguns passos nessa direção são necessários. Primeiramente, as DCNs devem ser reformuladas coerentemente com essa nova concepção. Em segundo lugar, há que se fomentar sua implantação pelos sistemas de ensino baseados num plano de financiamento, inclusive redirecionando as finalidades e metas do Proep. Tais perspectivas se colocam, ainda, no plano de disputa entre forças sociais. Por isto a análise das mediações e contradições de medidas mais recentes se torna necessária, motivando a pesquisa científica a tal compromisso ético e político.

\footnotetext{
${ }^{19}$ A Central Única dos Trabalhadores (CUT), por exemplo, sob a égide desses Programas, tem desenvolvido estudos sobre e educação integral de trabalhadores, alguns dos quais presentes no livro organizado por Costa e Conceição (2005).

20 Sobre este tema sugerimos a leitura de Frigotto, Ciavatta e Ramos (2005a).
} 


\section{Regime de colaboração entre os entes federados e a cobertura da Educação Profissional Municipal}

Em que pese o fato de mesmo antes da CF de 1988 ter-se notícia de intenções legais ${ }^{21}$ e prática de colaboração entre as esferas federadas, especificamente no campo educacional, é somente a partir desta carta que tal cooperação, em consonância ao espírito federativo, é oficialmente preconizada, nos termos de que "A União, os Estados, o Distrito Federal e os Municípios organizarão em regime de colaboração os seus sistemas de ensino" (Artigo 211, caput). Esta mesma redação se repetirá no Artigo 8 (caput) da LDBEN (BRASIL, 1996), quando aponta as formas de organização da educação nacional, embora, até os dias atuais, o regime em tela continue carecendo de pormenorização, o que poderia se dar por lei complementar.

A partir desse novo ordenamento jurídico que emerge entre o final dos idos de 1980 e a segunda metade de 1990, a colaboração passa a assumir caráter obrigatório na organização dos sistemas de ensino no Brasil, com vistas, especialmente, à minimização dos riscos de uma fragmentação desregulada da organização da educação nacional entre os sistemas de ensino, agora incluindo-se os sistemas municipais, já que, a partir de então, a autonomia passa a ser extensiva a todos os entes federados.

A tentativa de instituição dessa forma de relacionamento solidário entre os siste- mas de ensino irá repercutir no conjunto de práticas de gestão e de implementação de políticas públicas educacionais, por exemplo, em termos: i) da divisão de encargos relativos à oferta do Ensino Fundamental por Estados e Municípios, com ênfase na distribuição proporcional de responsabilidades pelas matrículas - com ou sem transferência de recursos financeiros e, ainda, na garantia de implementação de programas suplementares federais como o Programa Nacional de Alimentação Escolar (Pnae), o atual Programa Nacional de Apoio ao Transporte do Escolar (Pnate), além de outros mantidos pelo Fundo Nacional de Desenvolvimento da Educação (FNDE); ii) do planejamento, notadamente em termos da elaboração dos Planos Nacional, Estaduais e Municipais de Educação; iii) do estabelecimento de normas, no sentido da definição de competências e diretrizes educacionais, de padrões mínimos de oportunidades educacionais, da oferta de ensino com qualidade e, ainda, de avaliação do rendimento escolar (ABREU; SARI, 1999; FARENZENA, 2006; MACHADO, 2002; SARI; ABREU; RODRIGUES, 2001).

Embora a CF de 1988 (BRASIL, 1988) tenha sinalizado algumas incumbências educacionais da União (Artigo 211, §1 $1^{\circ}$ e dos Municípios (Artigo 211, §2), nada foi dito sobre os Estados. Essa lacuna será parcialmente preenchida pela EC 14/96 que, ao proporcionar nova redação ao artigo em questão, incluirá, entre outros aspectos, a menção de que "Os Estados e o Distrito Federal atuarão prioritariamente no ensino fundamental e médio", na EC 14/ 96, $\S 3^{\circ}$ (BRASIL, 1996a), sendo mantida a

\footnotetext{
${ }^{21}$ Vale ressaltar que tanto a Constituição de 1934, quanto a de 1946 já se aproximavam de princípios federalistas de colaboração na área educacional (MACHADO, 2002).
} 
definição e que os Municípios devem atuar "prioritariamente no ensino fundamental e na educação infantil" (EC 14/96, §2² ${ }^{22}$. Com isto, na LDBEN, os Estados são chamados a "definir, com os Municípios, formas de colaboração na oferta do ensino fundamental, as quais devem assegurar a distribuição proporcional das responsabilidades, de acordo com a população a ser atendida e os recursos financeiros disponíveis em cada uma dessas esferas do Poder Público", conforme LDBEN, Artigo 10, II (BRASIL, 1996b), enquanto que é reiterado aos Municípios seu comprometimento para com a oferta da "educação infantil em creches e pré-escolas, e, com prioridade, o ensino fundamental, permitida a atuação em outros níveis de ensino somente quando estiverem atendidas plenamente as necessidades de sua área de competência e com recursos acima dos percentuais mínimos vinculados pela Constituição Federal (BRASIL, 1988) à manutenção e desenvolvimento do ensino," 23 conforme LDBEN, Artigo 11, Inciso V (BRASIL, 1996b).

Independentemente desses aspectos, a

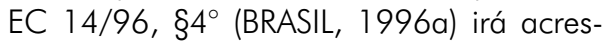
centar que "Na organização de seus sistemas de ensino, os Estados e Municípios definirão formas de colaboração, de modo a assegurar a universalização do ensino obrigatório", aspecto reiterado na LDBEN, Artigo
$5, \S 1^{\circ}$ (BRASIL, 1996b), agora com a indicação de que a participação da União no Regime de Colaboração será a de "assistência", no artigo $5, \S 1^{\circ}$, da LDBEN (BRASIL, 1996b) nestes termos, em coerência às funções "normativa, redistributiva e supletiva" previstas para fins da organização da educação nacional -, mas omisso em relação a um engajamento da União em mesmo nível de responsabilidades para com os demais entes federados, mesmo que resguardadas as prerrogativas de sua necessária ação coordenadora.

Entretanto, é possível afirmar que o Regime de Colaboração entre os entes federados - predicado por Gomes (2002, p. 18) como "um elo esquecido" - vem-se realizando em meio a um contexto no qual a translação de responsabilidades tem levado não à cooperação, mas a um quadro de concorrência entre os entes federados ${ }^{24}$, à desconcentração da administração educacional - das instâncias públicas para a sociedade civil - e, sobretudo, implicando privatizações, resultados da redefinição do papel do Estado no financiamento e oferta dos serviços de educação e, conseqüentemente, do deslocamento da fronteira entre as responsabilidades públicas e privadas (ADRIÃO; PERONI, 2005; GARCIA, 2002; AZEVEDO, 2001 a,b; GOMES, 2000; ABREU, 1998), com desdobramentos, também, no âmbito da Educação Profissional.

\footnotetext{
22 É, ainda, na esfera da EC 14/96 (BRASIL, 1996a) que se distinguem os termos relacionados i) às formas de colaboração entre União, Estados e Municípios; ii) à ação redistributiva ou supletiva das diferentes instâncias governamentais e, ainda, iii) à assistência técnica e financeira a ser prestada aos Estados e Municípios pela União (DUARTE, 1999a, 1999b).

${ }^{23} \mathrm{O}$ percentual mínimo a ser destinado à MDE pelos Estados e Municípios corresponde a 25\% sobre todos os impostos decrementado dos $15 \%$ de contribuição para o Fundef -, sendo que pelo menos $60 \%$ dessa aplicação deve ser dirigida ao Ensino Fundamental.

24 É importante destacar que o Ensino Fundamental, apesar de não se constituir prioridade dos Estados - e sim o Ensino Médio -, deve também estar assegurado por este mesmo ente. Para que essa superposição de esforços viesse a ser superada, deixando aos Municípios a priorização efetiva de todo o Ensino Fundamental (quer em termos de seus dois segmentos, quer do conjunto de seus ciclos), tornando os Estados, a um só tempo, "provedores por excelência do ensino médio" (GOMES, 2000, p. 39), estes últimos teriam que abdicar da possibilidade de aplicação dos recursos subvinculados ao Fundef, embora contribuindo para esse Fundo com os $15 \%$ previstos em lei.
} 
A par das poucas experiências academicamente avaliadas como bem sucedidas em torno da implementação do Regime de Colaboração (AGUIAR, 2002; GADOTTI, 2000; MACHADO, 2002), a literatura pertinente vem apontando múltiplas dificuldades para a sua difusão, como: i) a ausência de regras institucionais que aprofundem o estímulo a práticas cooperativas entre os entes federados; ii) a precariedade dos dados e informações sobre a realidade escolar no país; iii) a tradição autoritária nas relações intergovernamentais, aqui caracterizada pela tendência à centralização e concentração do poder decisório nas esferas federal e estaduais; iv) a carência de espaços oficiais de coordenação, barganha e deliberação conjunta entre as instâncias federadas, em que pesem as iniciativas tanto do Conselho Nacional de Secretários de Educação (Consed), quanto da União Nacional dos Dirigentes Municipais de Educação (Undime) nesta área ${ }^{25}$ (ABICALIL, 2001; ABREU; SARI, 1999; DUARTE, 2002; MACHADO, 2002; SOUZA; FARIA, 2003, 2004).

No que remete aos níveis e modalidades de ensino previstos na LDBEN, é possível afirmar que o Regime de Colaboração ocupa papel central nas discussões e práticas em torno da oferta da Educação Infantil e, em especial, do Ensino Fundamental (conforme anteriormente visto) - articuladamente à noção de ensino obrigatório -, como também no que remete ao atendimento do Ensino Médio (GOMES, 2000) e da Formação de Professores (AGUIAR, 2002; MACHADO, 2002), embora com menor freqüência de estudo. Todavia, deixa à margem dessas discussões e práticas a problemática da colaboração intergovernamental na oferta da Educação Profissional, conforme é possível depreender-se das discussões até aqui realizadas.

Se o Regime de Colaboração propugna o compartilhamento de responsabilidades e encargos educacionais entre os entes federados - podendo dar-se pela via de convênios, acordos, termos de cooperação, planos, entre outros instrumentos -, por que excluir desse pacto o atendimento às demandas sociais por Educação Profissional, notadamente identificáveis na esfera municipal? Nesta matéria, sob o espírito da cooperação e não por imposição legal, há de esperar uma atuação efetiva das redes estaduais e federal de Educação Profissional, pois até mesmo as questões entendidas como de:

responsabilidade local (municipal) se inserem, de algum modo, na esfera de responsabilidades do Estado e até da União, seja do ponto de vista da interdependência com as competências de coordenação, implementação e avaliação das políticas educacionais dessas instâncias, seja no que tange às responsabilidades fiscais e de financiamento, quando for o caso. É a idéia da interdependência e da co-responsabilidade intrínseca ao federalismo cooperativo (MACHADO, 2002, p. 127).

A análise de alguns dos quesitos do survey anteriormente qualificado permite afirmar que a Educação Profissional não vem sendo priorizada pelos Municípios fluminenses que participaram da pesquisa, de um lado, apresentando coerência em relação ao ordenamento jurídico que serve à definição

${ }^{25}$ Veja-se, por exemplo, Conselho Nacional de Secretários de Educação (1999). 
da competência dos sistemas municipais de ensino, mas, por outro, sugerindo a existência de deficit gerado pelo não-cumprimento do Regime de Colaboração entre os entes federados. Os Programas federais na área pouco ou nenhum impacto geram em âmbito local, enquanto que, em termos estaduais, a prática do Regime de Colaboração vem-se mostrando insuficiente em face, por exemplo, conforme sublinhado por Berta (2006), do ritmo de desenvolvimento econômico do Estado do Rio de Janeiro.

Verifica-se, entre o conjunto de ações desencadeados pelas SMEs para o atendimento das demandas locais de Educação Profissional, uma baixíssima incidência de respostas que indicam a oferta direta dos cursos $(15,4 \%)$ por estas autarquias. Predominantemente, o conjunto de respostas destaca esforços das SMEs na criação de infra-estrutura local $(46,1 \%)$, marcadamente em termos da oferta de espaço físico, material, transporte e, em alguns casos, alimentação, com vistas, de um lado, à celebração do Regime de Colaboração - com o Estado e a União - e à pactuação de parcerias - especialmente no âmbito do "Sistema S" 26 (30,8\%) - e, de outro lado, à cobertura direta da Educação Profissional (15,4\%), ação esta de menor freqüência de ocorrência ${ }^{27}$.
Apesar de ser possível apontar a criação de infra-estrutura local como ação típica dessas SMEs no campo da Educação Profissional, é flagrante o reclamo relacionado à carência de recursos que permitem sua consecução, tanto em termos financeiros (28,6\% das respostas), quanto materiais e pedagógicos - por exemplo, no que remete à inexistência local de docentes devidamente qualificados em determinadas áreas - $(28,6 \%)$, a par de outros entraves $(28,6 \%)$ relativos à descontinuidade dos cursos e, ainda, à ausência de parcerias que impliquem diversificação de suas áreas de Educação Profissional no Brasil ${ }^{28}$.

Na esfera da União, constata-se que nenhuma dessas localidades afirmou ter sido apoiada, no período 2001-2004 ${ }^{29}$, pelo Proep ou pelo Planfor, ações que na era FHC consistiram na principal materialização das políticas públicas do Governo Federal na área da Educação Profissio$\mathrm{nal}^{30}$. Em ambos os casos, as justificativas da ausência desses Programas concentramse tanto na afirmativa de que inexistiram convênios que os tivessem localmente viabilizado (55,5\% das respostas) - com ressalvas de que "gostariam de ser contemplados com Programas afins" -, quanto na declaração de que há o desconhecimento de sua finalidade $(44,5 \%)$.

\footnotetext{
${ }^{26}$ A designação "Sistema S" refere-se ao conjunto de instituições de Educação Profissional gerido pelo empresariado no Brasil, voltado para o atendimento de demandas relativas aos setores primário, secundário e terciário da economia, respectivamente: 0 Serviço Nacional de Aprendizagem Rural (Senar), o Serviço Nacional de Aprendizagem Industrial (Senai) e, no caso do setor terciário, o Serviço Nacional de Aprendizagem Comercial (Senac) e o Serviço Nacional de Aprendizagem do Transporte (Senat), também apoiados pelo Serviço Social da Indústria (Sesi), pelo Serviço Social do Comércio (Sesc), pelo Serviço Social do Transporte (Sest), entre outros.

${ }_{27}$ Quesito considerado por 43,7\% do universo de 16 localidades respondentes a esta temática Do total de respostas (13), 7,7\% não permitiram categorização devido à truncagem ou à ausência de coesão em relação ao enunciado do quesito.

${ }^{28}$ Quesito considerado por 37,5\% do universo de 16 localidades respondentes a esta temática. Do total de respostas a esse quesito (07), 14,2\% não permitiram categorização devido à truncagem ou ausência de coesão em relação ao enunciado do quesito.

29 É importante destacar que o período em questão (2001-2004) abarca os últimos dois anos (2001-2002) do segundo mandato do Governo FHC e os dois primeiros anos (2003-2004) do governo Lula.

${ }^{30}$ Quesito considerado por $75 \%$ do universo de 16 localidades respondentes a esta temática.
} 
Já na esfera estadual, parece haver algum tipo de cooperação na promoção da Educação Profissional, embora com reduzida indicação pelas SMEs respondentes. Ao indicarem o tipo de entidade com a qual - Município estabelece relacionamento para a oferta de Educação Profissional ${ }^{31}$, as respostas concentraram-se, majoritariamente, na parceria com o "Sistema S" $(35,3 \%)$ - em especial junto ao Senac, Sebrae e Senai - e, em menor número, no que remete ao exercício do Regime de Colaboração junto ao Governo do Estado do Rio de Janeiro $(17,6 \%)$ - como a Secretaria de Estado de Educação (SEE) e, sobretudo, a Secretaria de Estado de Ciência e Tecnologia (Secitec), neste último caso, em específico por intermédio da Fundação de Apoio à Escola Técnica do Estado do Rio de Janeiro (Faetec). Esta Fundação, presente em cerca de 34 Municípios fluminenses, ainda expõe deficits elevados de atendimento às demandas por novos profissionais no Estado, seja do ponto de vista da oferta de vagas - especialmente no interior -, seja no que remete à promoção de cursos sintonizados às perspectivas de crescimento local (BERTA, 2006) ${ }^{32}$.

\section{Considerações finais}

Finalmente, é possível afirmar que a cooperação advinda da União e dos Estados pela via do Regime de Colaboração, especialmente do Estado do Rio de Janeiro, vem-se mostrando tímida no atendimento da Educação Profissional, sobressaindo a crescente atuação do setor privado em sua cobertura, notadamente do "Sistema S", em conformidade a políticas mais amplas governamentais que vêm implicando desfinanciamento do ensino público no Brasil.

Demonstramos que o caráter obrigatório assumido pelo regime de colaboração na organização dos sistemas de ensino no Brasil visa, especialmente, à minimização dos riscos de uma fragmentação desregulada da organização da educação nacional entre os sistemas, incluindo-se os municipais. A tentativa de instituição dessa forma de relacionamento solidário entre os sistemas de ensino repercutiria no conjunto de práticas de gestão e de implementação de políticas públicas educacionais, como demonstraram Farenzena (2006), Machado (2002), Sari, Abreu e Rodrigues (2001) e Abreu e Sari, (1999). Note-se que a LDBEN é explícita somente quanto à obrigação de se definirem formas de colaboração entre os Estados e os Municípios na oferta do ensino fundamental, ficando a participação da União nessa colaboração restrita à assistência, em coerência às suas funções normativa, redistributiva e supletiva. Não há qualquer menção à educação profissional, inclusive porque a desvinculação dos cursos de formação profissional dos níveis de escolaridade, promovida pelo Decreto n. 2.208/ 97 (BRASIL, 1997), fez com que nenhum sistema educacional ficasse responsável diretamente por sua oferta.

A face do relacionamento entre os entes federados que acaba mostrando-se é a da concorrência ao invés da colaboração, associada à transferência de respon-

\footnotetext{
${ }^{31}$ Quesito considerado por 37\% do universo de 16 localidades respondentes a esta temática.

${ }^{32}$ Com freqüência unitária de resposta outras entidades foram assinaladas: empresas (5,9\%), instituições de ensino superior confessionais (5,9\%), organismos internacionais (5,9\%), ONGs (5,9\%), órgãos do próprio Município (5,9\%) e, ainda, instituições filantrópicas diversas $(5,9 \%)$, o que revela que, apesar da presença marcante do "Sistema S" nos Municípios, ocorre a busca por outras entidades que possam colaborar na cobertura da Educação Profissional.
} 
sabilidades das instâncias públicas para a sociedade civil - redundando, por vezes, em privatizações - como resultado da redefinição do papel do Estado no financiamento e oferta dos serviços de educação. A política de Educação Profissional é a expressão mais alardeante desse processo, inclusive porque, se existem discussões e práticas sobre o Regime de Colaboração envolvendo a educação infantil e os ensinos fundamental e médio, o mesmo não se pode dizer quanto a essa modalidade educacional. As dificuldades apontadas para a difusão desse regime ausência de regulamentação, de informações sobre a realidade escolar no país, e de espaços de coordenação entre as instâncias federadas; além da tradição autoritária nas relações intergovernamentais - precisa ser enfrentada.

A não-prioridade à Educação Profissional pelos municípios fluminenses, demonstrada pelos dados do survey, é expressão, dentre outras razões, do não cumprimento do Regime de Colaboração entre os entes federados. De fato, a baixíssima incidência de respostas que indicam a oferta direta dos cursos $(15,4 \%)$, limitando-se os esforços à criação de infra-estrutura local $(46,1 \%)$, visando, de um lado, à celebração do Regime de Colaboração como Estado e a União, sem muito sucesso e, por outro, à pactuação de parcerias, especialmente com "Sistema S" $(30,8 \%)$, iniciativas com maior êxito, corroboram nossas conclusões. Por fim, a observação de que os Programas federais na área pouco ou nenhum impacto geram em âmbito local e a insuficiência da ações do governo estadual, nos levam a concluir que a possibilidade de consecução do Regime de Colaboração no Estado do Rio de Janeiro, a partir dos municípios averiguados, somente será viabilizada mediante iniciativas concretas e diretas, articuladas entre si, do poder central e estadual.

A um só tempo identificou-se que a produção científica nesse campo ainda se mostra incipiente, não contemplando, especialmente, a reflexão sobre as formas predominantes de cooperação e de parcerias efetuadas pelos sistemas municipais de ensino junto aos demais entes federados e ao setor privado para a oferta da Educação Profissional.

Consideramos também que, em face da implantação do Fundeb, a importância desses estudos assume caráter emergencial, na medida em que tal vinculação de recursos contemplará o Ensino Médio e a EJA integrados à Educação Profissional.

De um modo ou de outro, destacamos a necessidade de melhor compreender-se a identidade da Educação Profissional no âmbito dos sistemas educacionais, particularmente municipal, e, assim, verificar a pertinência de se considerá-la, formalmente, como objeto de ação cooperada entre os entes federados. Compreender-se-ia, possivelmente, o paradoxo de, por um lado, essa modalidade ter merecido certa atenção pela legislação nacional e, por outro, não se constituir, de fato, em responsabilidade legal dos sistemas de ensino no Brasil, pelo menos até o presente momento. 


\section{Referências}

ABICALIL, C. A. O regime de colaboração na promoção da educação. In: CONFERÊNCIA NACIONAL DE EDUCAÇÃO, CULTURA E DESPORTO, 1., 2001, Brasília, DF. Anais...

Brasília: Câmara dos Deputados, Coordenações de Publicações, 2001.

ABREU, M. A Constituição Federal e a nova LDB: responsabilidades e sistemas de ensino. Cadernos Aslegis, Brasília, DF, v. 2, n. 4, p. 44-56, jan./abr. 1998.

ABREU, M.; SARI, M. T. Colaboração entre União, Estados, DF e Municípios na área da educação. Cadernos Aslegis, Brasília, DF, v. 3, n. 8, p. 9-15, maio/ago. 1999.

ADRIÃO, T.; PERONI, V. (Org.). O público e o privado na educação: interfaces entre estado e sociedade. São Paulo: Xamã, 2005.

AGUIAR, R. R. O regime de colaboração no Ceará. Em Aberto, Brasília, DF, v. 19, n. 75, p. 133-137, jul. 2002.

AZEVEDO, N. P. Política e gestão na educação municipal. In: CONFERÊNCIA NACIONAL DE EDUCAÇÃO, CULTURA E DESPORTO, 1., 2001, Brasília. Anais... Brasília, DF: Câmara dos Deputados, Coordenações de Publicações, 2001 a.

AZEVEDO, N. P. A UNDIME e os desafios da educação municipal. Estudos Avançados da USP, São Paulo, n. 42, p. 141-152, maio/ago. 2001 b.

BARDIN, L. Análise de conteúdo. Lisboa: Edições 70, 1977.

BERTA, R. Governo de transição: futuro secretário de educação quer fazer parcerias. 0 Globo, Rio de Janeiro, 25 nov. 2006. Caderno Rio, p. 31.

BONITATIBUS, S. G. Educação comparada: conceito, evolução, métodos. São Paulo: EPU, 1989.

BORGES, M. R. Municipalização do ensino: um desafio para a democratização do ensino fundamental? Nuances: estudos sobre educação, Presidente Prudente, v. 6, n. 6, p. 54-62, out. 2000 .

BRASIL. Constituição (1988). Constituição da República Federativa do Brasil. Diário Oficial [da] República Federativa do Brasil, Brasília, DF, 5 out. 1988.

Decreto $n^{\circ} .2 .208$, de 17 de abril de 1997. Regulamenta o $\S 2^{\circ}$ do art. 36 e os arts. 39 a 42 da Lei $n^{\circ}$ 9.394, de 20 de dezembro de 1996, que estabelece as diretrizes e bases da educação nacional. Diário Oficial [da] República Federativa do Brasil, Brasília, DF, 18 abr. 1997. 
BRASIL. Decreto $n^{\circ} .5 .154$, de 23 de julho de 2004. Regulamenta o $\S 2^{\circ}$ do art. 36 e os arts. 39 a 41 da Lei $n^{\circ}$ 9.394, de 20 de dezembro de 1996, que estabelece as diretrizes e bases da educação nacional, e dá outras providências. Diário Oficial [da] República Federativa do Brasil, Brasília, DF, 24 jul. 2004.

Emenda Constitucional $n^{\circ}$. 54, de 6 de dezembro de 2006. Dá nova redação aos arts. $7^{\circ}$, 23, 30, 206, 208, 211 e 212 da Constituição Federal e ao art. 60 do Ato das Disposições Constitucionais Transitórias. Diário Oficial [da] República Federativa do Brasil, Brasília, DF, 20 dez. 2006.

. Emenda Constitucional n. 14, de 12 de setembro de 1996. Modifica os artigos 34, 208, 211 e 212 da Constituição Federal e dá nova redação ao artigo 60 do Ato das Disposições Constitucionais Transitórias. Diário Oficial [da] República Federativa do Brasil, Brasília, DF, 13 set. 1996a.

. Lei n. 9.394, de 20 de dezembro de 1996. Estabelece as Diretrizes e Bases da Educação Nacional. Diário Oficial [da] República Federativa do Brasil, Brasília, DF, 23 dez. 1996 b.

BRASIL. Lei nº. 9.424, de 24 de dezembro de 1996. Dispõe sobre o Fundo de Manutenção e Desenvolvimento do Ensino Fundamental e de Valorização do Magistério, na forma prevista no art. 60, § $7^{\circ}$, do Ato das Disposições Constitucionais Transitórias e dá outras providências. Diário Oficial [da] República Federativa do Brasil, Brasília, DF, 1 jan. 1997.

. Lei $n^{\circ}$. 9.649, de 27 de maio de 1998. Dispõe sobre a organização da Presidência da República e dos Ministérios, e dá outras providências. Diário Oficial [da] República Federativa do Brasil, Brasília, DF, 28 maio 1998.

Lei Complementar $n^{\circ}$. 87, de 13 de setembro de 1996. Dispõe sobre o imposto dos Estados e do Distrito Federal sobre operações relativas à circulação de mercadorias e sobre prestações de serviços de transporte interestadual e intermunicipal e de comunicação, e dá outras providências (Lei Kandir). Diário Oficial [da] República Federativa do Brasil, Brasília, DF, 16 set. 1996c.

. Medida Provisória n. 339, de 28 de dezembro de 2006. Regulamenta o art. 60 do Ato das Disposições Constitucionais Transitórias e dá outras providências. Diário Oficial [da] República Federativa do Brasil, Brasília, DF, 29 dez. 2006.

- Ministério da Educação. Subsídios para o processo de discussão da proposta de anteprojeto de lei da educação profissional e tecnológica. Brasília, DF, 2005.

Disponível em: <http://www.mec.gov/setec>. Acesso em: 2 fev. 2005. 
CALDERÓN, A. I.; MARIM, V. Educação e políticas públicas: os conselhos municipais em questão. Teias: revista da Faculdade de Educação da UERJ, Rio de Janeiro, v. 3, n. 6, p. 39-47, jul./dez. 2002.

. Participação popular: a escola como alvo do terceiro setor. In: SOUZA, D. B.; $\overline{F A R I A}$, L. C. M. Desafios da educação municipal. Rio de Janeiro: DP\&A, 2003.

CASTRO, J. A. Financiamento da educação no Brasil, Em Aberto, Brasília, DF, v. 18, n. 74, p. 11-32, dez. 2001.

CONSELHO NACIONAL DE EDUCAÇÃO (Brasil). Câmara de Educação Básica. Parecer $n^{\circ}$. 30, de 12 de setembro de 2000. Define sistema de ensino dentro do ordenamento jurídico-administrativo, tendo-se como referência a organização da educação nacional. Diário Oficial [da] República Federativa do Brasil, Brasília, DF, 6 out. 2000.

CONSELHO NACIONAL DE SECRETÁRIOS DE EDUCAÇÃO (Brasil). Recomendações do Consed para o desenvolvimento do regime de colaboração. Terezina, 1999. Documento oficial.

CONTANDRIOPOULOS, A. Saber preparar uma pesquisa: definição, estrutura, financiamento. 2. ed. São Paulo: Abrasco; Rio de Janeiro: Hucitec, 1997.

COSTA, H.; CONCEIÇÃO, M. (Org.). Educação integral e sistema de reconhecimento e certificação educacional e profissional. São Paulo: Escola Sindical, CUT, 2005. v. 1, p. 19-62.

CURY, C. R. J. A educação como desafio na ordem jurídica. In: LOPES, E. M. T.; FARIA FILHO, L. M.; VEIGA, C. G. (Org.). 500 anos de educação no Brasil. 2. ed. Belo Horizonte: Autêntica, 2000.

CUNHA, L. A. Ensino médio e ensino profissional: da fusão à exclusão. Tecnologia e Cultura, Rio de Janeiro, v. 2, n. 2, p. 10-29, jul./dez. 1998.

DAVIES, N. Fundef: valorização da educação pública ou redistribuição da miséria. In: CONFERÊNCIA NACIONAL DE EDUCAÇÃO, CULTURA E DESPORTO, 1, 2001, Brasília, Anais... Brasília, DF: Câmara dos Deputados, Coordenações de Publicações, 2001 a. p. 210-234.

. O Fundef e as verbas da educação. São Paulo: Xamã, 2001b.

- Fundef e o orçamento da educação: desvendando a caixa preta. Campinas:

Autores Associados, 1999. 
DRAIBE, S. M. O redirecionamento das políticas sociais segundo a perspectiva neoliberal. In: MESSENBERG, G. et al. As políticas sociais no Brasil. Brasília, DF: Sesi, 1993. (Texto; 11).

DUARTE, M. R. T. Sistemas públicos de educação básica e relações intergovernamentais: a ação da União e a autonomia dos sistemas locais de ensino. Perspectiva: revista do Centro de Ciências da Educação da UFSC, Florianópolis, SC, v. 20, n. 2, p. 303-327, jul./dez. 2002.

- Limites à educação básica: expansão do atendimento e relação federativa. In: OLIVEIRA, D. A.; DUARTE, M. R. T. (Org.). Política e trabalho na escola: administração dos sistemas públicos de educação básica. Belo Horizonte: Autêntica, 1999b.

DUARTE, M. R. T. Limites à educação básica: expansão do atendimento e relação federativa. In: REUNIÃO ANUAL DA ANPEd, 22., 1999, Caxambu; GT Estado e Política Educacional no Brasil, 1999, Caxambu. Anais... Rio de Janeiro: Associação Nacional de Pós-graduação e Pesquisa em Educação, 1999a. 1 CD-ROM.

. Limites à municipalização na educação básica. Revista de Administração Municipal: municípios, Rio de Janeiro, v. 45, n. 224, p. 32-38, mar./abr. 2000.

FARENZENA, N. A política de financiamento da educação básica: rumos da legislação brasileira. Porto Alegre: Editora da UFRGS, 2006. (Série Política e Gestão da Educação, 2).

FONSECA, M. O financiamento do Banco Mundial à educação brasileira: vinte anos de cooperação internacional. In: DE TOMMASI, L.; WARDE, M. J.; HADDAD, S. (Org.). O Banco Mundial e as políticas educacionais. São Paulo: Cortez, 1996.

FRIGOTTO, G. Universidade pública, trabalho e projeto de desenvolvimento no Brasil sob o pêndulo da regressão social. In: RISTOFF, D.; MOLL, J. Universidade e mundo do trabalho (Org.). Brasília, DF: Instituto Nacional de Estudos e Pesquisas Educacionais Anísio Teixeira, 2006. (Coleção Educação Superior em Debate; 3).

FRIGOTTO, G.; CIAVATTA, M.; RAMOS, M. N. A política de educação profissional no Governo Lula: um percurso histórico controvertido. Educação \& Sociedade, Campinas, v. 26, n. 92, p. 1087-1113, out. 2005a.

FRIGOTTO, G.; CIAVATTA, M.; RAMOS, M. N. (Org.). Ensino médio integrado: concepção e contradições. São Paulo: Cortez, 2005b.

GARCIA, W. E. Federalismo e gestão educacional no Brasil: notas para debate. Em Aberto, Brasília, DF, v. 19, n. 75, p. 70-77, jul. 2002. 
GOMES, C. A. Gestão educacional: para onde vamos? Em Aberto, Brasília, DF, v. 19, n. 75, p. 9-22, jul. 2002.

- Regime de colaboração intergovernamental: alternativa para maioridade do ensino médio. Cadernos de Pesquisa, São Paulo, n. 109, p. 25-41, mar. 2000.

GONÇALVES, R. A. O financiamento da educação: um sistema em desequilíbrio. Cadernos de Pesquisa, São Paulo, n. 103, p. 14-52, mar. 1998.

GUIMARÃES, J. L.; PINTO, J. M. R. A demanda pela educação infantil e os recursos disponíveis para o seu financiamento. Em Aberto, Brasília, DF, v. 18, n. 74, p. 92-105, dez. 2001.

IANNI, O. Estado e planejamento econômico no Brasil. Rio de Janeiro: Civilização Brasileira, 1991.

JACOBI, P. Políticas sociais e ampliação da cidadania. 2. ed. Rio de Janeiro: Ed. FGV, 2002.

LAVILLE, C.; DIONNE, J. A construção do saber: manual de metodologia da pesquisa em ciências humanas. Porto Alegre: Artmed; Belo Horizonte: Ed.UFMG, 1999.

MACHADO, M. A. M. A gestão da educação básica na perspectiva do regime de colaboração: algumas notas. Em Aberto, Brasília, DF, v. 19, n. 75, p. 123-132, jul. 2002.

MARINI, R. M. Dialética da dependência. Rio de Janeiro: Clacso: Vozes, 2000.

MELLO, D. L. Governo e administração municipal: a experiência brasileira. Revista de Administração Pública, Rio de Janeiro, v. 35, n. 2, p. 79-96, mar./abr. 2001.

MENEZES, R. M. Processo de gasto e descentralização na política educacional brasileira. Em Aberto, Brasília, DF, v. 18, n. 74, p. 58-71, dez. 2001.

MONLEVADE, J. A. Avaliação e perspectivas do financiamento da educação pública no Brasil. In: CONFERÊNCIA NACIONAL DE EDUCAÇÃO, CULTURA E DESPORTO, 1., 2001, Brasília. Anais... Brasília, DF: Câmara dos Deputados, Coordenações de Publicações, 2001.

Financiamento da educação na Constituição Federal e na LDB. In: BRZEZINSKI, I. (Org.). LDB interpretada: diversos olhares se entrecruzam. São Paulo: Cortez, 1997.

MONTAÑO, C. Terceiro setor e a questão social: crítica ao padrão emergente de intervenção social. 2. ed. São Paulo: Cortez, 2003. 
NOGUEIRA, M. A. A dimensão política da descentralização participativa. São Paulo em Perspectiva, São Paulo, v. 11, n. 3, p. 8-19, jun./set. 1997.

REPÚBLICA Federativa do Brasil. Jornal do Brasil, Rio de Janeiro, 2 out. 2006. País, p. A7.

RAMOS, M. N. O público e o privado na educação profissional: as políticas do MEC. In: ADRIÃO, T.; PERONI, V. (Org.). O público e o privado na educação: interfaces entre estado e sociedade. São Paulo: Xamã, 2005.

RIO DE JANEIRO (Estado). Anuário estatístico do Estado do Rio de Janeiro: 2003. Rio de Janeiro: Fundação Cide, 2003. 1 CD-ROM.

SARI, M. T.; ABREU, M.; RODRIGUES, M. Regime de colaboração. In: CONFERÊNCIA NACIONAL DE EDUCAÇÃO, CULTURA E DESPORTO, 1., 2001, Brasília. Anais... Brasília, DF: Câmara dos Deputados, Coordenações de Publicações, 2001.

SINGER, P. A crise do "milagre": interpretação crítica da economia brasileira. São Paulo: Paz e Terra, 1989.

SOUZA, D. B.; FARIA, L. C. M. Limites e possibilidades da educação municipal pós-LDB (9.394/96). In: Janeiro: DP\&A, 2003. (Org.). Desafios da educação municipal. Rio de

- Políticas de financiamento da educação municipal no Brasil (1996-2002): das disposições legais equalizadoras às práticas político-institucionais excludentes. Ensaio: avaliação e políticas públicas em educação: revista da Fundação Cesgranrio, Rio de Janeiro, v. 12, n. 42, p. 564-582, jan./mar. 2004.

. Projeto de pesquisa mapa estadual das reformas educacionais pós-LDB 9.394/ 96: leituras, posicionamentos e ações das secretarias municipais de educação do Estado do Rio de Janeiro (2001-2004). Rio de Janeiro: Nuepe, UERJ, 2002.

VERHINE, R. E. Um experimento chamado Fundef: uma análise do seu desempenho no cenário nacional e no contexto da Bahia, Educação Brasileira, Brasília, DF, v. 22, n. 45, p. $121-146$, jul./dez. 2000.

VIEIRA, S. L.; FREITAS, I. M. S. Política educacional no Brasil: introdução histórica. Brasília, DF: Plano, 2003.

Recebido em: 24/01/2007

Aceito para publicação em: 23/03/2007 